\title{
The Influence of Work Environment, Motivation and Competence to Work Performance and the Impact on Lecturer Performance in Higher Education
}

\author{
Ian Zulfikar \\ \{ian.zulfikar@civitas.unas.ac.id\}, Universitas National, Jakarta, Indonesia.
}

\section{Suryono Efendi}

\{suryono.efendi@yahoo.com\}, Universitas National, Jakarta, Indonesia.

\section{Heri Suheri}

\{heri.suheri@gmail.com\}, Universitas National, Jakarta, Indonesia.

\section{Dwia Ariestina Pulubuhu}

\{dwiatn@unhas.ac.id\}, Hasanuddin University, Makassar, Indonesia.

\section{Rahman Kadir}

\{rahmankadir90@yahoo.com\}, Faculty of Economics and Business, Hasanuddin University, Makassar, Indonesia.

\section{Tadjuddin Parenta}

\{tparenta@yahoo.com\}, Faculty of Economics and Business,Hasanuddin University, Makassar, Indonesia.

\begin{abstract}
Quality lecturer performance is needed by universities. The purpose of this study was to analyze the influence of the work environment, motivation, and competence on the job satisfaction and its impact on the performance of lecturers. The results of this study indicate that the variables of work environment, motivation, and competence directly have a positive and real effect on job satisfaction. Variable job satisfaction does not directly have a positive and real effect on the performance of lecturers. It is very urgent to pay attention to how to restore and encourage satisfaction so that it can have a positive effect on the performance of lecturers. Then the high devotion nature of each lecturer, then the higher education should give awards to lecturers who have high devotion, improve training, and maintain an attendance with more professionalism, Also continue to stimulate lecturers who conduct research and communityservice.
\end{abstract}

Keywords:

Higher Education Work Environment, Motivation, Competence, Job Satisfaction and Lecturer Performance.

Article Received: 18 October 2020, Revised: 3 November 2020, Accepted: 24 December 2020

\section{Introduction}

\subsection{Preliminary}

The institution is an educational institution both public and private that offer formal educational activities ranging from preschool to higher education, both general and specific. The institution is also a social institution to become agents of socialization continued after the institution of the family.

Higher education plays an active role in improving the capacity of the individual potential of human resources (HR). Tri dharma principles must continue to be implemented and actualized follow scientific developments in society .In a dynamic society, things can change with this happening for their needs in a diverse society, not only in the level of knowledge but also the specific skills required in the workplace.

The working environment is the social, psychological, and physical effect on the faculty 
in carrying out day-to-human not out of the state of the surrounding environment, between man and the environment there is a very close relationship. In this case, people will always try to adapt to different circumstances surrounding environment. Similarly, when doing the work, the lecturer as a human being cannot be separated from the various circumstances surrounding their place of work, the work environment. During the work, each faculty will interact with a variety of conditions contained in the working environment that is expected to add faculty job satisfaction for itself.

Job satisfaction will drive improved performance of lecturers or employees. In general, the performance of lecturers among others influenced by several factors, such as work environment, motivation and competence through job satisfaction and ultimately improve the performance of lecturers.

The lecturers are professional educators and scientists with the main task of transforming, develop, and disseminate science and technology through education, research and community service (7). So, the good lecturer's performance parameters of course refer to the achievement of the results of the Tri Dharma College.

The increasingly fierce competition in some colleges require every college has an advantage in the quality of human resources (HR), including the work environment, motivation, and competence to improve job satisfaction which in turn will improve the performance of lecturers.

\subsection{Literature review}

\subsubsection{Work Environment}

The working environment is something in the environment that may affect the workers themselves in performing tasks such as temperature, humidity, ventilation, lighting, noise, cleanliness of the workplace and the adequacy of the means of work equipment (1).

Meanwhile, work environment is an environment where employees perform their daily work. From some of the definitions above it can be concluded that the working environment is everything that is around the workers/lecturers can affect job satisfaction in performing their duties so that would be obtained maximum work (2).

\subsubsection{Motivation}

Motivation is the willingness to issue a high level of effort for the purpose of the organization is conditioned by the effort's ability to satisfy some individual needs (3).

Meanwhile, work motivation is a potential force that is inside a human being, which can be developed alone or developed by a number of outside forces that essentially revolves around the financial rewards and non-financial, that may affect the results positively or negatively, depending on the situation and the conditions faced by the persons concerned. Therefore, commonly referred to as the driving motivation or morale in relation to the work environment. Someone who is highly motivated, that is, those who carry out substantial efforts in order to support the purposes of the production of its unity, and the organization where he works.

\subsubsection{Competence}

Competence or capability means the capacity of an individual to perform various tasks in a job (4). Ability is a current assessment of what can be done person. Robbins person's overall ability to divide into two groups of factors: intellectual ability, the skills needed to perform a variety of mental activity, thinking, reasoning, and problem solving. Smart individuals more likely to be a leader in a group. There are seven dimensions that make up the most frequently mentioned intellectual ability is a number, verbal comprehension, perceptual speed, inductive reasoning, deductive reasoning, spatial visualization, and memory.

Based on the understanding of the above, it can be concluded that competence is the ability to work to integrate the knowledge, skills, abilities and personal values based on experiences and lessons learned in order to implement their duties in a professional, effective and efficient 


\subsubsection{Job Satisfaction}

Correspondence between one's expectations arising and rewards provided there is satisfaction. So that job satisfaction is also closely related to the theory of justice, psychological agreement and motivation (4), defines job satisfaction as a general attitude of an individual to work in a job where a person is required to interact with colleagues and superiors, follow the rules and policies of the organization, meet the performance standards. Several important theories on job satisfaction is a manifestation of the results of studies that determine how the employees can be satisfied quoted (5):

\section{2.a.1 Meeting the NeedsTheory}

Meeting the Needs Theory (Need Fulfillment Theory) According to this theory, employee satisfaction is met or not depends on the needs of this employee. Need form of physical, safety, social, esteem and self-actualization (3). Furthermore, there are three requirements that are relevant in the workplace: the need for achievement, need for power and the need for affiliation. Employees will feel satisfied if he got what he needed (3). The greater the employee's needs are met, the more satisfied the employee anyway. Vice versa, if the employee's needs are not met, employees will be dissatisfied.

\section{2.a.2 Two Factor Theory ofHerzberg}

Two-factor theory was developed by Frederick Herzberg. He use Abraham Maslow's theory as a reference point. Two factors can cause a sense of satisfaction or dissatisfaction according to Herzberg, the factors of maintenance (maintenance factors) and motivational factors (motivation factors). Maintenance factors or also called dissatisfies, hygiene factors, job context, extrinsic factors administration and policy of the company, the quality of supervision, relationship with supervisor, the relationship with the subordinate, wages, job security, working conditions and status. While motivating factor called the satisfiers, motivators, job content, intrinsic factors, include the encouragement of achievement, recognition, advancement, growth opportunities, and responsibilities.

There are five dimensions that can affect job satisfaction, namely (6):

a. The work itself, that is how to provide interesting tasks for employees, the opportunity to learn, and the opportunity to acceptresponsibility.

b. Coworkers, namely co-workers have technical skills and easy to cooperate or support socially. Coworkers friendly and cooperative will give job satisfaction of employees as happy in theirwork.

c. Salary significant effect on job satisfaction but also more broadly describe the various dimensions ofsatisfaction.

d. Promotion opportunity, a chance to gain a higher position or careerdevelopment.

e. Supervision, the supervisor's ability to provide technical guidance work and attitude.

\subsubsection{Performance Lecturer}

Performance or performance is an overview of the level of achievement of implementing a program of activities or policies in realizing the goals, objectives, vision and mission of the institution or organization that is poured through a strategic planning organization. Performance is the result of the quality and quantity of work accomplished by someone employee in carrying out their duties in accordance with the responsibilities given to him (5).

Dimensional or performance standards or factors evaluated in the implementation of the work includes total volume of work, quality of work, adaptability and the ability and willingness to cooperate as expressed:

1.2.5.1 Quantity of Work: with regard to the volume of work that can be donesomeone.

1.2.5.2 Quality of Work: with respect to the accuracy and completeness of thework.

1.2.5.3 Initiative: with regard to the desire to move forward, independent, full responsibility for thejob.

1.2.5.4 Adaptability: with regard to the ability to 
respond and adapt to changing circumstances.

\subsubsection{Cooperation: with regard to} the ability and willingness to cooperate with the leaders and fellow coworkers.

Lecturers have adequate minimum academic qualification of a master's program graduate diploma or undergraduate and graduate doctoral program to program pascasarjana. It in article 46 paragraph 3 says that every person who has expertise with a good performance, be appointed as a lecturer. Lecturers are required to have academic qualifications, competencies, certificates, education, physical and spiritual health, and meet the other qualifications required by higher education unit in charge of the place, as well as having the ability to achieve national education goals(7).

Lecturer is a determinant of educational success through performance on the level of institutionally, instructional, and experiential. Faculty performance is not only demonstrated by the work, but also demonstrated by the behavior in the work. Faculty performance can also be shown how great the competencies required by the the are met. Competence includes pedagogical competence, personal competence, social competence and professional competence(7).

Faculty performance indicators can be seen from the satisfaction of students and parents, student achievement, social behavior and the presence of lecturers.

\section{Research Methodology}

\subsection{Chart Framework}

Meanwhile, Framework is a conceptual model of how theory relates to the various factors that have been identified as important (8). So thus the frame is an underlying understanding that the other understandings, an understanding of the most fundamental and became the foundation for every thought or a form of the overall process of research to be conducted. The framework tersebut can be seen from figure 1 .

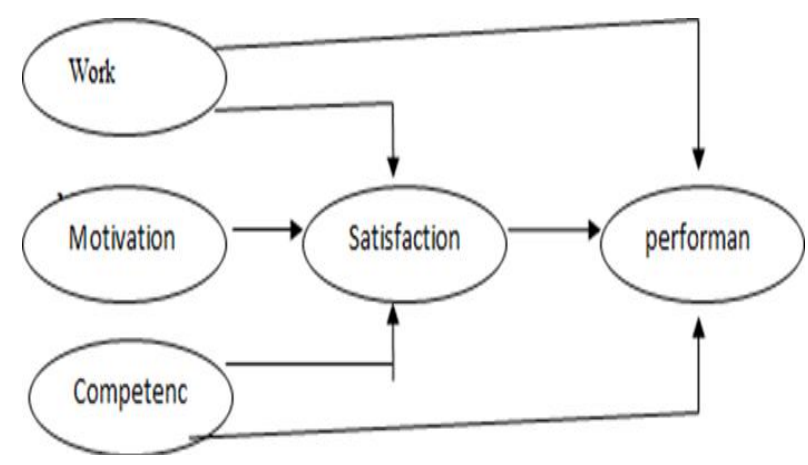

Fig. 1. Chart Framework

\subsection{FrameworkModel}

Framework model of a part used to describe the relationship between variables that will form a model. This study wants to examine the influence of the Work Environment variables (X1), motivation (X2), and Competence (X3) on job satisfaction (Y1) and its impact on the performance of lecturers (Y2) at the National University in Jakarta. The picture is as follows: 


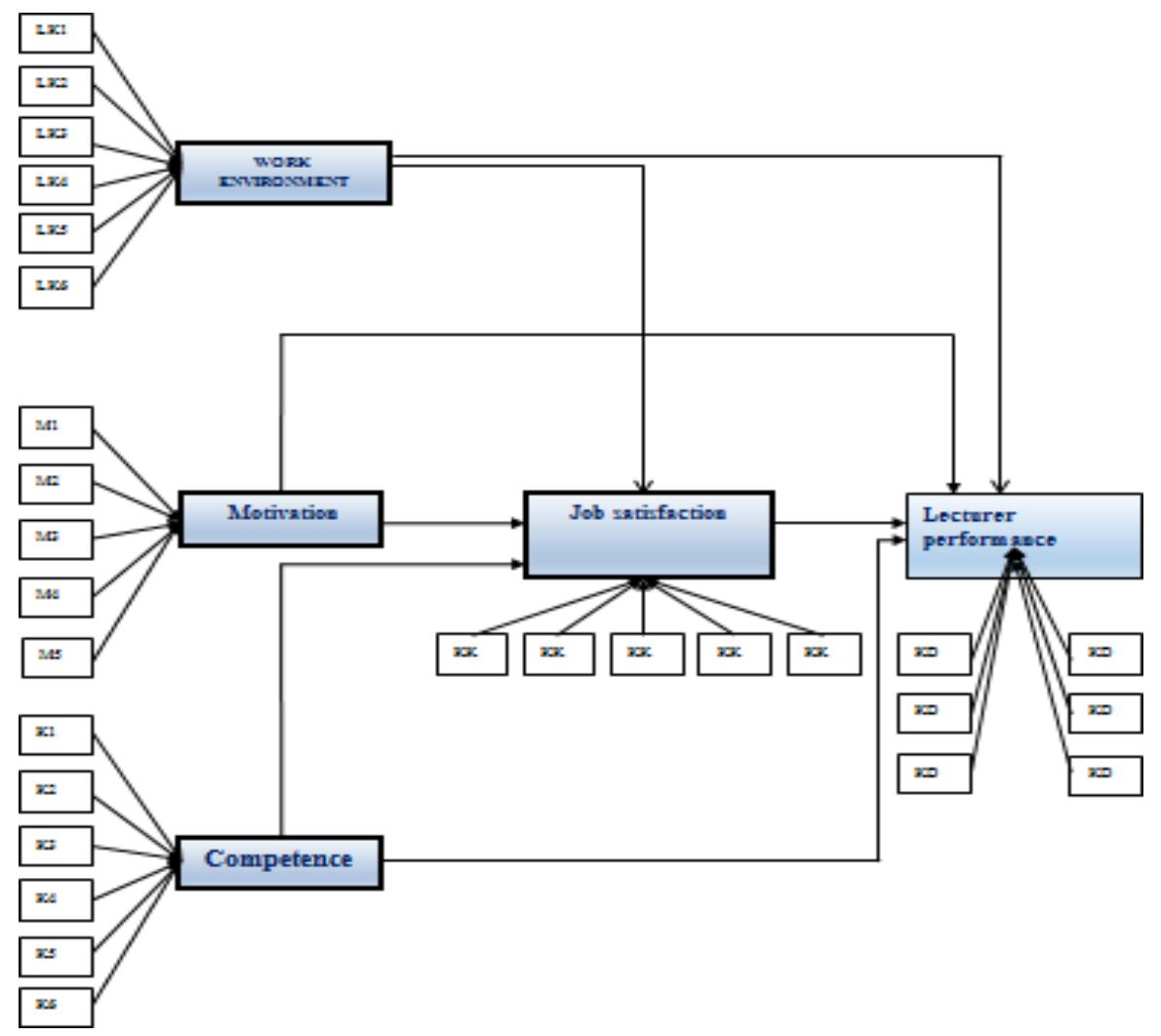

Fig. 2. Chart Framework Model

\subsection{Researchhypothesis}

Based on the formulation problems, the research model and premise, as mentioned earlier, it is tentative statements of the issues in question are presented in the following hypothesis:

Ha1: Direct working environment have a positive effect on jobsatisfaction.

Ha2: Motivation direct have a positive effect on jobsatisfaction.

Ha3: Competence direct have a positive effect on jobsatisfaction.

Ha4: Environmental have a positive influence on the performance oflecturers.

Ha5: Motivation direct have a positive effect on the performance oflecturers.

Ha6: Competence direct have a positive effect on the performance oflecturers.

Ha7: Job satisfactions havean effect on the performance oflecturers.

Ha8: The work environments through job satisfaction have a positive effect on the performance oflecturers.

HA9: Motivation through job satisfaction and a real positive effect on the performance oflecturers.

Ha10: Competence through job satisfaction and a real positive effect on the performance oflecturers.

\subsection{Researchdesign}

Analytical method to answer the hypothesis using Structural Equation Modeling (SEM) with AMOS.

\subsection{Unit ofAnalysis}

Unit of Analysis is a lecturer of five accredited university located in South Jakarta (National University, University of Pancasila, Gunadarma University, Muhammadiyah University Prof.DR.Hamka, Atma Jaya Catholic University of Indonesia). Sampling techniques in this study using simple random sampling, considering the sample jumplah scattered and very large. The method is widely used in SEM is the maximum likelihood (ML) recommended sample size is $100-200$.

\subsection{Method of collectingdata}

Data collection methods used in this study 
are: the data are processed in order to test the hypothesis of primary data obtained from the respondents on the list of questions

\subsection{Variables andIndicators}

(questionnaire) that are closed are distributed to the respondents. The questionnaire using Likert scale 1 - 5 .

Table 1. Variables and Indicators

\begin{tabular}{|c|c|c|}
\hline Variables & Operational definition & Indicator \\
\hline Environment (X1) & $\begin{array}{l}\text { The working environment is } \\
\text { something in the environment } \\
\text { that may affect the workers } \\
\text { themselves in performing tasks } \\
\text { such as temperature, humidity, } \\
\text { ventilation, lighting, noise, } \\
\text { cleanliness of the workplace and } \\
\text { the adequacy of the means of } \\
\text { work equipment. (1) }\end{array}$ & $\begin{array}{l}\text { 1. Lighting/Light in the } \\
\text { workplace } \\
\text { 2. The air temperature in the } \\
\text { workplace } \\
\text { 3. Air humidity in the } \\
\text { workplace } \\
\text { 4. Care and support leadership } \\
\text { 5. Cooperation between } \\
\text { departments }\end{array}$ \\
\hline Motivation (X2) & $\begin{array}{l}\text { Motivation is defined as a } \\
\text { willingness to issue a high level } \\
\text { of effort for the organization's } \\
\text { goals are conditioned by the } \\
\text { effort's ability to meet the } \\
\text { individual needs something (3) }\end{array}$ & $\begin{array}{l}\text { 6. Fluencycommunication } \\
\text { 1. Responsible } \\
\text { 2. Achievement (task with } \\
\text { cleartargets) } \\
\text { 3. Opportunities for } \\
\text { advancement } \\
\text { 4. Recognition of Performance } \\
\text { 5. A challengingjob }\end{array}$ \\
\hline Competence (X3) & $\begin{array}{l}\text { Competency or capability means } \\
\text { the capacity of an individual to } \\
\text { perform various tasks in a job } \\
\text { (4). }\end{array}$ & $\begin{array}{l}\text { 1. Knowledge } \\
\text { 2. Skills } \\
\text { 3. Behaviorattitude } \\
\text { 4. Duty capability Social } \\
\text { 5. Ability (managing emotions) } \\
\text { 6. Personality }\end{array}$ \\
\hline Job Satisfaction & $\begin{array}{l}\text { Job satisfaction is how workers } \\
\text { feel about his job. Job satisfaction }\end{array}$ & $\begin{array}{l}\text { 1.Salaries } \\
\text { 2.Work comfortability }\end{array}$ \\
\hline$(\mathrm{Y})$ & $\begin{array}{l}\text { is affected by several aspects of } \\
\text { the work, } \\
\text { wages/salaries. } \\
\text { conditions, } \\
\text { coworking } \\
\text { security, aswell as the opportunity } \\
\text { to move forward. (3) }\end{array}$ & $\begin{array}{l}\text { 3. The pride of the Institution } \\
4 \text { Opportunities to advance } \\
\text { 5. Authority and Flexibility }\end{array}$ \\
\hline $\begin{array}{c}\text { Lecturer } \\
\text { Performance (Y2) }\end{array}$ & $\begin{array}{l}\text { According to the law that the } \\
\text { principal task is to implement } \\
\text { education professors and } \\
\text { teaching in higher education, } \\
\text { research and community service. } \\
\text { Plan, implement the learning }\end{array}$ & $\begin{array}{l}\text { 1. Education and Teaching } \\
\text { 2. Research } \\
\text { 3. Community Service } \\
\text { 4. Upgrading } \\
\text { 5. Acting Objective } \\
\text { 6. Professional Competence. }\end{array}$ \\
\hline
\end{tabular}



process and assess and evaluate
the learning outcomes.
Improving and developing the
academic qualifications and
competence on an ongoing basis
in line with developments in
science, technology, and art. (7)

\subsection{MechanicalAnalysis}

\subsubsection{Hypothesis testing}

That testing to determine the effect of the research variables. Testing done using t- value or Critical Ratio (CR) in this case at a rate of $5 \%=$ 1.96 with a significance level of 0.05 (9).

\section{Results and Discussion}

\subsection{Test Results AssumptionsSEM}

Assumptions that must be met or that would be acceptable under the SEM analysis, among others: the normality of the data, outliers and multicollinearity and singularity.

\subsection{Normality Test Data}

Testing normality of the data is done by observing the value of skewness and kurtosis of the data used, if the value of the critical ratio (cr) on the skewness and kurtosis of the data is in the range between \pm 2.58 (9). Evaluation is done by using the criteria of normality ratioskewness critical value and kurtosis value. Data summarized normal distribution if the value of the critical ratio (cr) and multivariate skewness value below

2.58. Results of testing the normality of the data as follows:

From the data processing is seen that in a univariate normal distribution of data for each variable still has one of the $\mathrm{CR}$ skewness or kurtosis value under the range \pm 2.58 and multivariate critical ratio value is equal to 2,398 is below the range of \pm 2.58 . Thus, the use of research data which meets the requirements of the normality of the data or studies have concluded that the normal distribution of data so that it can be continued next steps.

\subsection{0utlier TestData}

Outlieris the condition of observation of the data that has unique characteristics that aesthetically very different from other observations and appeared in the form of extreme value, either for a single variable or variables combination. To multivariate outlier detection is done with regard to the value mahalanobis distance. The criteria used is based on the value of Chi-Square on the degrees of freedom (degree of freedom) 24, which is a significant number of indicators at the level of $\mathrm{p}<0.001$ (9). Value Mahalonabis distance $\square \square^{2}(0.001 ; 24)=51.179$. This means that all the cases that have mahalanobis distance greater than 51179 is a multivariate outlier. The following is the output mahalanobisdistanceFull Fit Model using AMOS program 22.

Based on the analysis shows that the value mahalanobis nothing above 51.179 then concluded there are no outliers in the data used in this research. Results of a complete outlier data processing can be found in appendix 4 .

\subsection{Construct Validity}

Simultaneously construct validity indicated by uer (extract size variance) $\geq 0.50$.

$$
\mathrm{UER}=\frac{\sum \mathrm{FMS}^{2}}{\sum \mathrm{FMS}^{2}+\sum \text { Error }}
$$

Based on the calculation uer it is known that the competence and job satisfaction variables used in this study simultaneously generally have good construct validity with uer value> 0.50 . While motivation variable and performance of lecturers have uer marginal value ie 0.48 and 0.43 but CR (Critical Ratio) $>2.0$ and probability $(\mathrm{p})<5$, it can 
be concluded indicators work environment, motivation, competence, job satisfaction and performance of lecturers can be used as a shaper / measure each latent variable.

\subsection{Test Reliability Construct}

Reliability is a measure of internal consistency of indicators that show the formation variable degrees to which each indicator indicates a variable shape. Their reliability test the questions / instruments used in research to obtain the desired information can be trusted as a data collector and be able to reveal the actual information field.

Reliability and stability of the construct describes the ability of measuring instruments used so that reliable and can be used to predict (predictability) .Uji simultaneously construct reliability is shown by the size of the composite reliability(Urk) $\geq 0.70$.

$$
\mathrm{Urk}=\frac{\sum(\mathrm{FMS})^{2}}{\sum(\mathrm{FMS})^{2}+\sum(\text { Error })}
$$

The criteria which the reliability is less than 0.60 is less, whereas it can be said both 0.70 and 0.80 above is said to be very good. So we can conclude all indicators work environment, motivation, competence, job satisfaction and performance can be quite good lecturer. Based on Urk calculations indicate that the latent variables used in this study had good construct reliability with Urk value of $0.60-0.83$. thus the latent variables used in this study had high reliability positive constructs with Urk $\geq 0.60$.

\subsection{SEManalysis}

3.6.1 Confirmatory Factor Analysis (Confirmatory Factor Analysis / CFA

Confirmatory factor analysis aimed at testing the dimensions undimensionalitas of forming respective latent variables. In the confirmatory factor analysis of latent variables is to test the significance of the indicators that make up the latent variables are analyzed from the critical ratio or t-value (CR) and probabilitas from respectively positively and significantly influential indicator / significant to the latent variables.

According Joreskog and Sorborn (1993) CFA used to test unidimensional, Validity and reliability of the measurement model constructs that cannot be measured directly. Technic more accurate to examine the validity and reliability of confirmatory factor analysis (Joreskog and Sorbom, 1993). A variable is said to have good validity of the constructs or latent variables, if:

3.6.1.1 $\mathrm{T}$ load factor (loading factors) is greater than the critical value (or $\geq 1.96$ ),

3.6.1.2 The default factor loadings (standardized loading factors) $\geq 0.70$.

\subsubsection{Confirmatory Factor Analysis (CFA) Working Environment}

In the confirmatory factor analysis of exogenous variables Working Environment is to test the significance of the indicators that make up the Working Environment exogenous variables were analyzed from the value of standardized regression regression weight and the weight of each indicator .

Based on the results of analysis showed that the dimensions and indicators of the Work Environment variables all have the value of $\mathrm{CR}$ (Critical Ratio)> 1.96 and significant with $\mathrm{p}=$ 0.001 or below the probability (p) $<0.05$ (Ghozali, 2013). While entirely valid indicator for the value of the standard loading factor (FMS) $>0.50$ so it is not necessary modification of the model and construct plausible WorkingEnvironment.

Based on the coefficient of determination (R2) Shows that each of the indicators work environment variable has a value $r$ square that contribute positively to the variable. R-square value indicator illumination of $50.8 \%$, the value of $r$ square temperature indicator/temperature of $52.6 \%$, the value of $43.8 \%$ moisture square $\mathrm{r}, \mathrm{r}$ square value leadership attention and support of $63.6 \%$, r-square value of cooperation between partsof $60.6 \%$ and r-square value amounted to 
$34.1 \%$ smooth communication.

It can be concluded that indicator light, temperature / temperature, humidity, attention and support of the leadership, cooperation and smooth communication between the parts of each positive effect on the latent variables, of $50.8 \%$, $52.6 \%, 43.8 \%, 63.6 \%, 60.6 \%$ and $34.1 \%$. This suggests that there are other indicators that influence the work environment variables in addition to the indicators used in this study because some indicators still have r-square value below $50 \%$.

\subsubsection{Confirmatory Factor Analysis (CFA) Motivation}

In the confirmatory factor analysis of exogenous variables motivation is to test the significance of the indicators that make up the exogenous variables is analyzed from the value of standardized regression regression weight and the weight of each indicator.

Based on the results of the analysis showed that the dimensions and indicators of motivation variables all have the value of $\mathrm{CR}$ (Critical Ratio)> 1.96 and significant with $p$ $=0.001($ marked $* * *)$ or under the probability $(\mathrm{p})$ $<0.05$ (Ghozali, 2010). While entirely valid indicator for the value of the standard loading factor (FMS) $>0.50$ so it is not necessary modification of the model and construct plausible motivation.

Based on the value of the coefficient of determination (R2) shows that each indicator variable has a value of $r$ square motivation to contribute positively to the variable. R- square value indicator of responsibility was $26.5 \%$, value of r-square of $48.5 \%$ achievement indicators, r-square value opportunities for advanced $49.1 \%$, r-square value recognition of the performance of $42.2 \%$ r-square value of the performance challenges of $42.9 \%$,

Thus we can conclude responsibilities, achievements, opportunities for advancement, recognition of performance and challenges affecting the performance of each of the latent variables, $26.5 \%, 48.5 \%, 49.1 \%, 42.2 \%$ and
42.9\%. This suggests that there are other indicators that influence the motivation variable in addition to the indicators used in this study because some indicators still have r-square value below $50 \%$.

\subsubsection{Confirmatory Factor Analysis (CFA) Competence}

In the confirmatory factor analysis of exogenous variables are the competence of testing the significance of the indicators that make up the exogenous variables analyzed Competence of regression weight grades and standardized regression weight of each indicator variable has a value of $\mathrm{CR}$ entirely Competence (Critical Ratio) $>1.96$ and significant with $\mathrm{p}=$ 0.001 (marked $* * *$ ) or under the probability $(\mathrm{p})$ $<0.05$. While entirely valid indicator for the value of the standard loading factor (FMS) $>0.50$ so it is not necessary modification of the model and construct a decent compensation.

Based on the value of the coefficient of determination (R2) shows that each indicator variable has a value of $r$ square competence can contribute positively to the variable. $\mathrm{R}$ - square value of knowledge indicator $73.3 \%$ r-square value of skills indicator by $13.9 \%$, the value of $r$ square behavioral attitudes $85.6 \%$, the value of $r$ square stints ability by $60, \%$, r-square value of social skills by $72,5 \%$ and r-square value by $45 \%$ personality.

It can be concluded indicator of knowledge, skills, attitude, behavior, ability to perform tasks, social skills and personality of each affects the latent variables $73.3,13.9 \%, 85.6 \%, 60 \%, 72.5 \%$ and $45 \%$. This suggests that there are other indicators that influence the variable competence in addition to the indicators used in this study because some indicators still have r-square value below $50 \%$.

\subsubsection{Confirmatory Factor Analysis (CFA) Job Satisfaction}

In the confirmatory factor analysis of endogenous variables job satisfaction is to test the significance of the indicators that make up 
the exogenous variables is analyzed from the value of standardized regression regression weight and the weight of each indicator.

Based on the results of the analysis showed that the dimensions and indicators of job satisfaction variables all have the value of $\mathrm{CR}$ (Critical Ratio)> 1.96 and significant with $\mathrm{p}=$ 0.001 (marked $* * *$ ) or under the probability $(\mathrm{p})$ $<0.05$ (9). While entirelyvalid indicator for the value of the standard loading factor (FMS) $>0.50$ so it is not necessary modification of the model and Job Satisfaction deserved.Based on the value of the coefficient of determination (R2) shows that each job satisfaction indicator variable has a value of $r$ square that can contribute positively to the variable. R-square value indicator salaries by $39 \%$, the value of $\mathrm{r}$ square work comfort indicator by $44 \%$, the value of r-square of pride for the institution of $53.9 \%, r$-square value the opportunity to advance by $61.9 \%$, and the value of r-square of authority and flexibility of $62.5 \%$.

It can be concluded indicator of knowledge, skills, attitude, behavior, ability to perform tasks, social skills and personality of each affects the latent variable by $39 \%, 44 \%, 53.9 \%, 61.9 \%$ and $62.5 \%$. This suggests that there are other indicators that influence the variable competence in addition to the indicators used in this study because some indicators still have r-square value below $50 \%$.

\subsubsection{Confirmatory Factor Analysis (CFA) Lecturer Performance}

In the confirmatory factor analysis of endogenous variables Lecturer performance is to test the significance of the indicators that make up the exogenous variables is analyzed from the value of regression weight and standardized regression weight of each indicate.

According to the table 4:21 to note that the dimensions and indicators of performance variables Lecturers all have value CR (Critical Ratio)> 1.96 and significant with $p=0.001$ (marked $* * *$ ) or under the probability $(\mathrm{p})<0.05$ (Ghozali 2010). While the indicators all have good validity or value is valid because the value of the standard loading factor (FMS) $>0.50$ so it is not necessary modification of the model and construct plausible Nurse Performance.

Based on the value of the coefficient of determination (R2) shows that each faculty performance indicator variable has a value of $r$ square that can contribute positively to the variable. R-square value indicators of education / teaching of $39.2 \%$, r-square value of research indicator of $46.1 \%$, the value of public service square $\mathrm{r} 56.2 \% \mathrm{r}$-square value increases the ability of $27.3 \%$, the value of $\mathrm{r}$ square act objectively amounted to $60.1 \%$. and r-square value of professional competence by $20.4 \%$.

It can be concluded indicator of knowledge, skills, attitude, behavior, ability to perform tasks, social skills and personality of each affects the latent variables by $39.2 \%, 46.1 \%, 56.2 \%, 27.3 \%$, $60.1 \%$ and $20.4 \%$. This suggests that there are other indicators that influence the variable competence in addition to the indicators used in this study because some indicators still have rsquare value below $50 \%$.

\subsubsection{Analysis of Structural Equation Modeling (SEM) Full Model}

Result test data processing for the full model SEM analysis are presented in the following figure: 


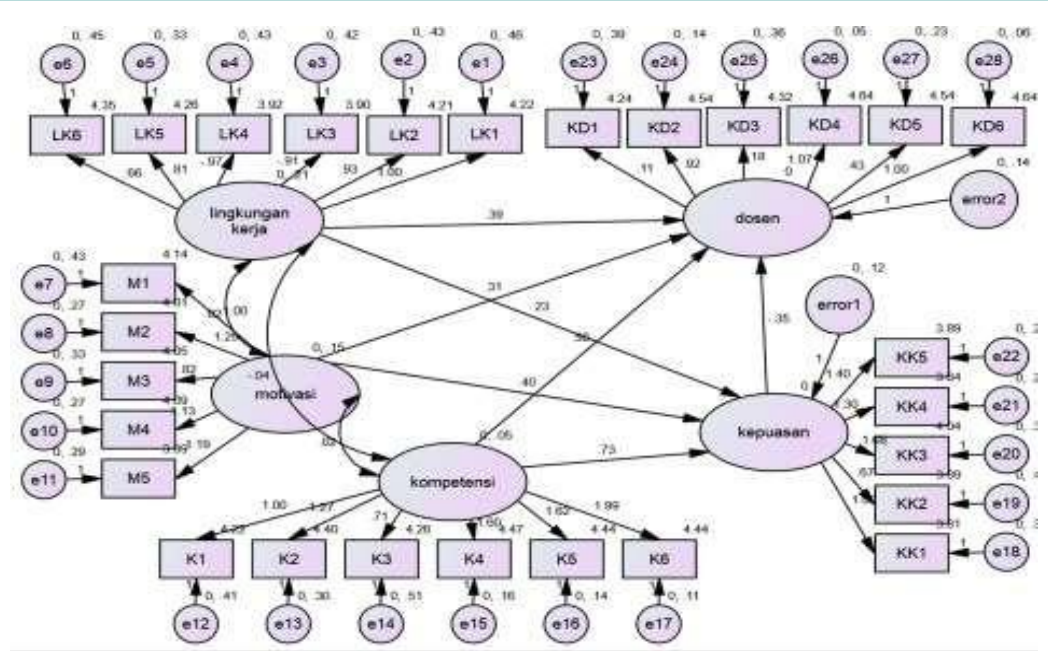

Source: Sports SEM results in Appendix 4

Fig. 2. Full Image Model SEM

\subsection{Structural EquationModel}

After the test Confirmatory Factor Analysis and testing of a full model fit, the next stage is to look at the relationship of influence and exogenous and endogenous latent variables. Influences and relationships latent variable exogenous and endogenous is a structural equation Job Satisfaction (KK) explain the causal relationship between changes $(\mathrm{KK})$ in the event of changes in the independent variable, namely the Working Environment (LK), motivation (M) and competence $(\mathrm{K})$ or $\mathrm{KK}=\mathrm{f}(\mathrm{LK}, \mathrm{M}, \mathrm{K})$. While the structural equations Lecturer Performance (KD) explain the causal relationship between performance Lecturer (KD) with the Working Environment (LK) Motivation (M), Competence $(\mathrm{K})$ and job satisfaction $(\mathrm{KK})$ or $\mathrm{KD}$ $=\mathrm{f}(\mathrm{LK}, \mathrm{M}, \mathrm{K}, \mathrm{KK})$.

Equation 1: KK LK + $0264=02770296 \mathrm{M}+\mathrm{K}$

$\mathrm{SE}=>(0.290)$

$\mathrm{R} 2=0.454$

Equation 2: $\mathrm{KD}=0.289+0.252 \mathrm{LK} \mathrm{K}+\mathrm{M}+$ $0.285 \mathrm{KD} 0.223$

$\mathrm{SE}=>(0.277)$

Based on the equation 1 above can be explained as follows:

\subsubsection{Variance Extranted (VE) to construct a} working environment

$=(0.7122+0.6832+0.6622+0.7882+0.6582$

$+0.5842) / 6=0.46$ or $46 \%$
According to the table 4:18 to indicators of work environment where LK1, LK2, LK3, LK4, LK5 and LK6 has a P-Value $=0: 46>0.05$ so that it can disimpulkanbahwa indicators LK1, LK2, LK3, LK4, LK5 and LK6 significantly shape the work environment factors.

\subsubsection{Variance Extranted (VE) to constructmotivation}

$=(0.5152+0.6962+0.4912+0.6492+0.6552)$ / $5=0.37$ or $37 \%$

According to the table 4:18 to indicators of work environment where M1, M2, M3, M4, and M5 has a P-Value $=0: 37>0.05$ so that it can be concluded that the indicators M1, M2, M3, M4, and M5 significantly shape the motivation factor.

\subsubsection{Variance Extranted (VE) to construct competence}

$=(0.3402+0.4712+0.2242+0.6832+0.7102$ $+0.8112) / 6=0.34$ or $34 \%$

According to the table 4:18 to indicators of work environment where $\mathrm{K} 1, \mathrm{~K} 2, \mathrm{~K} 3, \mathrm{~K} 4$, and $\mathrm{K} 5$ has a P-Value $=0: 34>0.05$ so that it can disimpulkanbahwa indicator $\mathrm{K} 1, \mathrm{~K} 2, \mathrm{~K} 3, \mathrm{~K} 4$, and K5 significantly shape the competence factor.

\subsubsection{Variance Extranted (VE) to construct jobsatisfaction} $=(0.5722+0.3952+0.6432+0.7432+0.7612)$ 
/ $5=0.41$ or $41 \%$

4.18 based on tables for indicators work environment where KK1, KK2, KK3, KK4, and KK5 has a P-Value $=0.41>0.05$ so that it can disimpulkanbahwa indicators KK1, KK2, KK3, KK4, and KK5 significantly shape factor of job satisfaction.

3.7.5 Variance Extranted (VE) to construct the performance of lecturers

$=(0.8652+0.3632+0.9012+0.1282+0.7302$ $+0.0782) / 6=0.37$ or $37 \%$

According to the table 4:18 to indicators of work environment where KD1, KD2, KD3, KD4, and KD5 has a P-Value $=0: 37>0.05$ so that it can disimpulkanbahwa indicators KD1, KD2, KD3, KD4, and KD5 significantly shape factor lecturer performance.

\subsection{Hypothesistest}

Next will be testing the hypothesis, as proposed in the previous chapter. Tests carried out using t-value or Critical Ratio (CR) in this case at a rate of $5 \%=1.96$ significance level 0.05 in Weight Regression of the data processing, as presented below:

\subsubsection{The influence of the working environment on job satisfaction lecturer}

Based on the results of the analysis can be seen that the value of the critical ratio (CR) to influence the work environment variables on job satisfaction is equal to3,205>1.96 (the critical value for the degree of confidence of $95 \%$ ) with a probability value (p) $0.003>0.05$ and the regression coefficient the direct effect of 0230 (positive) so that it can be concluded that the better the work environment then a lecturer job satisfaction will increase and vice versa, the worse the working environment then working kepusan lecturers will decrease. It can be concluded that the working environment positive and significant effect on job satisfaction lecturer.

\subsubsection{Motivational influence on job satisfaction lecturer}

Analysis value of the critical ratio (CR) for motivation variable influence on job satisfaction is equal to $2,808>1.96$ (the critical value for the degree of confidence of $95 \%$ ) with a probability value (p) of $0.005>0.05$ and the regression coefficient influence indirectly, of 0405 (positive) so that it can be concluded that the direct motivation and a real positive effect on job satisfaction lecturer thus effect hypothesis motivation on job satisfaction can beaccepted.

With the direct proof that motivation and a real positive effect on the Performance of lecturers, this implies the theory if there is an increase motivation scores result in an increase of faculty performance. Conversely, if a decline in motivation scores directly affect positively and significantly to the decline in performance scores lecturers.

\subsubsection{Influence on job satisfaction faculty competence}

Analysis value of the critical ratio (CR) for competence variables influence on job satisfaction is equal to $2,446>1.96$ (the critical value for the degree of confidence of $95 \%$ ) with a probability value (p) of $0.014>0.05$ and the regression coefficient influence indirectly, of 0732 (positive) so that it can be concluded that the direct competence and a real positive effect on job satisfaction. Thus the hypothesis competence and real positive effect on job satisfaction lecturer, isacceptable.

\subsubsection{The influence of the working environment on the performance of lecturers}

Analysis value of the critical ratio (CR) to influence the work environment variables on the performance of the lecturer is equal to 2,898> 1.96 (the critical value for the degree of confidence of $95 \%$ ) with a probability value (p) of $0.004>0.05$ and the regression coefficient the direct effect of 0389 (positive) so that it can be concluded that the better the work environment, the performance of the lecturers will be increased and vice versa. Thusitcanbeconcludedthattheworkingenvironmen 
tpositiveandsignificanteffecton the performance of the lecturers.

\subsubsection{Motivational influence on the performance of lecturers}

Analysis can be seen that the value of the critical ratio (CR) for motivation variable influence on the performance of the lecturer is equal to 2,167> 1.96 (the critical value for the degree of confidence of $95 \%$ ) with a probability value $(p)$ of $0.030>0.05$ and the regression coefficient influence indirectly, of 0313 (positive) so that it can be concluded that the direct motivation and a real positive effect on the performance of lecturers. Thus the hypothesis motivation positive and significant impact on job satisfaction lecturer at the National University, Jakarta, is acceptable.

\subsubsection{Influence of the performance of lecturers' competencies}

Analysis value of the critical ratio $(\mathrm{CR})$ to influence the performance of faculty competence variable is equal to $1,989>1.96$ (the critical value for the degree of confidence of 95\%) with a probability value (p) of $0.047>0.05$ and the regression coefficient influence indirectly, of 0577 (positive) so that it can be concluded that the better the competence of the faculty performance will increase. Thus competence positive and significant impact on the performance oflecturers.

\subsubsection{The influence of job satisfaction on the performance of lecturers}

Analysis value of the critical ratio (CR) to influence job satisfaction variables on the performance of the lecturer is at -2382> 1.96 (the critical value for the degree of confidence of $95 \%$ ) with a probability value (p) of $0.017>0.05$ and a coefficient regression direct influence of 0346 (negative) so that it can be concluded that it is inversely proportional. Setap increased satisfaction actually reduce performance. Work is due to the high saturation factor in the sense of dissatisfaction that dragged on larut.Seseorang which has a protracted discontent, not easy to feel. Performance improvement instead of job satisfaction rather than an environment variable work, motivation, and especially the competence of the faculty itself. The uniqueness of the performance improvement arises from the nature of devotion of each lecturer at different levels. Thus the job satisfaction is not positive and significant effect on the performance oflecturers.

\subsubsection{Influence of Working Environment Working through the satisfaction of the performance of lecturers}

Analysis showed that the influence of the working environment through job satisfaction on the performance of the lecturers have an indirect influence the value of the direct influence of 0.230 . With 0,042 . Thus unacceptable that the working environment positive and significant effect on the performance of lecturers through job satisfaction.

Thus the hypothesis of the working environment through job satisfaction and a real positive effect on the performance of faculty of the National University, Jakarta.If an increase in the working environment score through job satisfaction will lead to increased performance of the lecturer.

\subsubsection{Effect of Motivation Working through the satisfaction of the performance of lecturers}

Motivational influence on the performance of lecturers through job satisfaction visits Analysis can be seen that the influence of motivation through job satisfaction on the performance of the lecturers have an indirect influence value amounted 0,04. Direct influence of 0,405 . So unacceptable that motivation positive and significant effect on the performance of lecturers through job satisfaction.With so the hypothesis of motivation through job satisfaction and a real positive effect on the performance of the lecturer, is acceptable.If there is an increase motivation score through job satisfaction will lead to improved performance of lecturers and 
vice-versa.

\subsubsection{Influence of competence Working through the satisfaction of the performance of lecturers}

Analysis showed that the effect of competence through job satisfaction on the performance of the lecturers have an indirect influence the value of the direct influence of 0,732.Dengan 0,148.Sedangkan thus unacceptable that the competence of positive and significant effect on the performance of lecturers through an increase in job satisfaction score of competence through satisfaction work will result in improved performance of lecturers and viceversa.

\subsection{ConclusionHypothesis}

Here is the conclusion hypothesis Based on the results of the study proved or disproved and magnitude $\mathrm{CR}$ and propabilitas (P) with a summary as follows:

Table 2. Conclusion Hypothesis

\begin{tabular}{|c|c|c|}
\hline $\begin{array}{l}\text { Hypothes } \\
\text { is }\end{array}$ & $\begin{array}{l}\text { Proven / } \\
\text { Not Proven }\end{array}$ & Information \\
\hline \multirow[t]{2}{*}{ Ha 1} & & A sum of $3,205 C R>1.96$ \\
\hline & Proven & P. $0.003>0.05$ \\
\hline \multirow[t]{2}{*}{ Ha 2} & & A sum of $2,808 \mathrm{CR}>1.96$ \\
\hline & Proven & P. $0.005>0.05$ \\
\hline \multirow[t]{2}{*}{ Ha 3} & & A sum of $2,446 \mathrm{CR}>1.96$ \\
\hline & Proven & P. $0.014>0.05$ \\
\hline \multirow[t]{2}{*}{ Ha 4} & & A sum of $2,898 \mathrm{CR}>1.96$ \\
\hline & Proven & P. $0.004>0.05$ \\
\hline \multirow[t]{2}{*}{ Ha 5} & & A sum of $2,167 \mathrm{CR}>1.96$ \\
\hline & Proven & P. $0.030>0.05$ \\
\hline \multirow[t]{2}{*}{ На 6} & & A sum of $1,989 \mathrm{CR}>1.96$ \\
\hline & Proven & P. $0.047>0.05$ \\
\hline \multirow[t]{2}{*}{ Ha 7} & & Amounting CR -2382> 1.96 \\
\hline & Not proven & $\begin{array}{l}\text { P. } 0.017>0.05 \\
\text { the indirect effect of } 0,042 \text {. }\end{array}$ \\
\hline Ha 8 & Proven & $\begin{array}{l}\text { Influence directly at } 0.230 \text {. Significant. } \\
\text { indirect effect of } 0.043 \text {. }\end{array}$ \\
\hline Ha 9 & Proven & $\begin{array}{l}\text { Significant direct influence amounted to } \\
0.405\end{array}$ \\
\hline \multirow[t]{2}{*}{ На 10} & & the indirect effect of 0,148 . \\
\hline & Proven & Influence directly at 0.732 Significant \\
\hline
\end{tabular}

Source: Appendix though 4

It can be concluded that the most dominant variables affect the performance of the lecturer is variable competence, in accordance with the highest perception of respondents to study questionnaires. While job satisfaction is directly does not affect the performance of lecturers.

4 Conclusions and Suggestions

\subsection{Conclusion}

Work Environment, Motivation and Competence direct and positive effect on job satisfaction. Work Environment, Motivation and Competence direct and positive effect on performance. Work Environment, Motivation, and Job Competence through gratification of positive effect on performance. 


\subsection{Suggestion}

Based on the results of proving this hypothesis, some suggestions to the researcher in connection with the renewal of the practice of human resource management 1 as follows:

Motivation direct and tangible positive effect on job satisfaction. At the motivation variable is the smallest indicator (M5) the challenge of employment (79\%). Addressing saturated routines that must be carried out new innovations. Similarly, the direct competence and a real positive effect on job satisfaction. Personality / exemplary (K6) is the lowest indicator number $(76 \%)$ it should be a concern of the lecturers to continue to improve the personality and ideals. While job satisfaction is directly no positive effect on the performance of lecturers 1 . It is very urgent to consider how to restore and encourage satisfaction in order to influence positively on the performance of lecturers. In connection that encourages faculty performance is variable influences the working environment, motivation, and especially the competence of lecturers. Then the properties of high devotion of each faculty, then it should give awards to professors who possess high devotion.

\section{References}

[1] Isyandi, B. Manajemen Sumber Daya Manusia Dalam Perspektif Global. Pekanbaru: Unri Press,2004.

[2] Mardiana. Manajemen Produksi. Jakarta : Badan Penerbit IPWI, 2005.

[3] Robbins. Organizational Behavior.TenthEdition.Edisi Indonesian. Jakarta: PT Gramedia Grasindo, 2006.

[4] Judge, Robbins and. Robbins and Judge. Jakarta: Salemba Empat, 2008. Buku 2.

[5] Mangkunagara, Anwar Prabu. Perilaku dan Budaya Organisasi. Bandung: Rafika Adi Tama, 2008.

[6] Luthans, Fred. Perilaku Organisasi. Yogyakarta: Andy Offset, 2009. Edisi10.

[7] Law Of Republic Indonesia. Indonesia: s.n., 2005. 14.

[8] Sugiyono. Metode Penelitian Kuantitatif,
Kualitatif dan R\&D. Bandung: Alfabeta, 2011.

[9] Ghozali, Imam. Aplikasi Analisis Multivariate dengan Program IBM SPSS. Semarang: Badan Penerbit Universitas Dipenogoro,2013. 